\title{
Who do you look like? Evidence of facial stereotypes for male names
}

\author{
Melissa A. Lea \\ Millsaps College, Jackson, Mississippi \\ AND \\ Robin D. Thomas, Nathan A. Lamkin, and Aaron Bell \\ Miami University, Oxford, Ohio
}

\begin{abstract}
The present research provides evidence that people use facial prototypes when they encounter different names. In Experiment 1, participants created face exemplars for fifteen common male names, subsets of which were endorsed as good examples by a second set of participants. These most typical faces were morphed to create facename prototypes. In Experiment 2, participants matched one of the names to each of the prototype faces from Experiment 1. Participants' matching choices showed convergence in naming the prototypes for many of the names. Experiment 3 utilized these same prototypes in a learning task designed to investigate if the face-name associations revealed in Experiment 2 impacted the learnability of the names. Participants learned face-name pairings that had a higher association (based on frequencies from Experiment 2) faster than pairings with a low association. Results suggest a more direct relationship between faces and names than has been previously proposed.
\end{abstract}

Choosing a name for a forthcoming baby occupies a good deal of time for most expectant parents. Many worry about things like how their child's name will shape the future opportunities of the child, or how susceptible to teasing the name renders the child (Satran \& Rosenkrantz, 2004). Few worry about whether the name will provoke a facial stereotype in the minds of others $(\mathrm{hmm}$... he doesn't look like a "Bob"), but, as the present research suggests, this may be yet another potential worry to have when one selects a name for one's progeny. This is an especially provocative suggestion as names are usually chosen before or immediately after birth, certainly before any knowledge becomes available of what the child may look like when they are adults.

That names can provoke stereotypes in terms of personality is not a particularly new observation in the realm of social psychology. People associate a given name with certain characteristics, such as ethicality, success (see, e.g., Bruning, Polinko, \& Buckingham, 1998; Mehrabian, 2001), gender (Kasof, 1993), and ethnicity (Maclin \& Melpass, 2001). It has also been shown that certain facial characteristics are associated with personality traits (Shevlin, Walker, Davies, Banyard, \& Lewis, 2003), desirability (Goldstein, Chance, \& Gilbert, 1984), gender (Perrett et al., 1998), and race (Lindsay, Jack, \& Christian, 1991). What we have not yet documented is that certain faces seem to go with certain names, and vice versa. Motivated by the tip-of-the-tongue (TOT) phenomena in which almost all aspects of a person's identity may be recalled with the exception of the name, models of face perception have typically treated names as an unimportant, disconnected stepchild of the recognition process, occurring only after semantic and episodic retrieval has been completed (e.g., Bruce \& Young, 1986; McWeeny, Young, Hay, \& Ellis, 1987; Valentine, Brennen, \& Bredart, 1996). On the other hand, there are hints in the literature that the naming process itself may be an important contributor of recognition. For example, when asked to learn face-name-occupation mappings, participants who are allowed to choose names that "fit" individual stimuli in the set learned faster and recalled the names better than participants for whom those names were arbitrarily assigned by the experimenter (Cohen, 1990).

We explore the hypothesis that names may be tightly bound to sets of facial characteristics in the experiments that follow. To motivate this thesis, consider the two faces displayed in Figure 1. Suppose one of these men is Tim and the other Bob. Who would you guess is Tim or Bob? We have presented these pictures to large undergraduate classes and asked the students to match the names Tim and Bob with the faces in Figure 1. Without fail, students almost unanimously choose the face on the left as "Tim" and the face on the right as "Bob." The strength of this effect for these stimuli suggested that there may be strong associations between facial characteristics and names. The present experiments sought to formalize this observation.

To document a face-name association and possible cognitive consequences, we first ask participants to cre-

R.D.Thomas, thomasrd@muohio.edu 



Figure 1. Photographs of two men used to illustrate a face-name relationship. Audience is asked, Which man is named "Tim" and which is named "Bob"? Audience members overwhelmingly agree that the man on the left is named "Tim" and the man on the right is named "Bob."

ate faces, for specific male names, using face creation software analogous to that used in eyewitness investigations. After processing these exemplars to obtain facename prototypes, we then ask a second set of participants to match the constructed faces to the set of names used in the stimulus creation stage. We hypothesized the face-name mapping of the first set of participants to be recovered in this matching task with the second set of participants. Finally, in a third experiment, we explore the possibility that good face-name pairings facilitate learning of names for faces whereas poor matches (i.e., those that violate the face-name links established in the face creation and matching tasks) lead to worse learning performance.

\section{EXPERIMENT 1}

\section{Face Prototype Creation for Specific Names}

\section{Method}

Participants. One hundred fifty Caucasian participants ${ }^{1}(90$ women) enrolled in an introductory psychology class at Miami University created the original set of faces. A second (different) set of 42 participants ( 18 women) were involved in selecting the best representatives for the names. Participants received research experience credit.

Materials and Procedures. Fifteen male names were selected for study (Table 1). These names were chosen because they appear in the population with equal frequency (Kasof, 1993) and were agespecific for the populations used in the study (i.e., college aged; Bruning et al., 1998) (see note 1).

Participants used the software program Faces (Version 3.0; IQ Biometrix, 1998) to create their faces. The participant began by playing a face recognition game for fifteen minutes to help him or her learn the aspects of the program. The participant then created a practice face ("Mike"). Participants were asked to use only those features necessary for creating a face (eyes, nose, and mouth) and were asked to avoid the optional components available with the program, such as glasses and facial hair. Finally, the participants were given one of the randomly assigned names (Table 1) and then asked to create a representative face. This session generally lasted about $1 \mathrm{~h}$.

The initial group of 150 participants each generated one face for one of the 15 names. This yielded 10 potential exemplars per name. Because it has been shown that the external features of unfamil- iar faces are used for recognition over any internal features (see, e.g., Ellis, Shepard, \& Davis, 1979), all of the hair was replaced with a standard hairstyle. In addition, any distinctive features (e.g., glasses) that may have inserted in spite of instructions were removed (e.g., Valentine \& Bruce, 1986). The set was then standardized using Morpher 3.0 to occupy roughly the same spatial extent and gray scale range by aligning at least 100 critical points (e.g., eyes, nose) from each composite. A second group of participants was asked to review the set of generated faces for each name to determine which exemplars fit the category; that is, they sorted the faces into good examples and bad examples of the name. Often, some of the generated faces appeared strange or even nonfacelike due to difficulty the participants may have had in the selection of facial features. Figure 2 provides examples of faces that were deemed to be good examples and those that were rejected.

\section{Results}

Exemplar faces that were endorsed as good examples of a name category by more than $50 \%$ of the participants in the second group were retained. This resulted in an average of $4.1(s=1.0)$ faces for each name to be morphed (averaged) into a name prototype. Figure 3 displays the face prototypes for the 15 names. These prototype faces served as the stimulus set for the subsequent matching task in Experiment 2.

\section{EXPERIMENT 2 Matching}

Using the faces constructed in Experiment 1, we can determine whether people will agree that a specific face should be called by one name. Participants matched each of the prototype faces from Experiment 1 to one of the 15 names in Table 1. Two possible outcomes will support the hypothesis that there is a relationship between

\begin{tabular}{lllll}
\multicolumn{5}{c}{$\begin{array}{c}\text { Table 1 } \\
\text { Names }\end{array}$} \\
\hline Andy & Brian & Joe & Justin & Rick \\
Bill & Dan & John & Mark & Tim \\
Bob & Jason & Josh & Matt & Tom \\
\hline
\end{tabular}



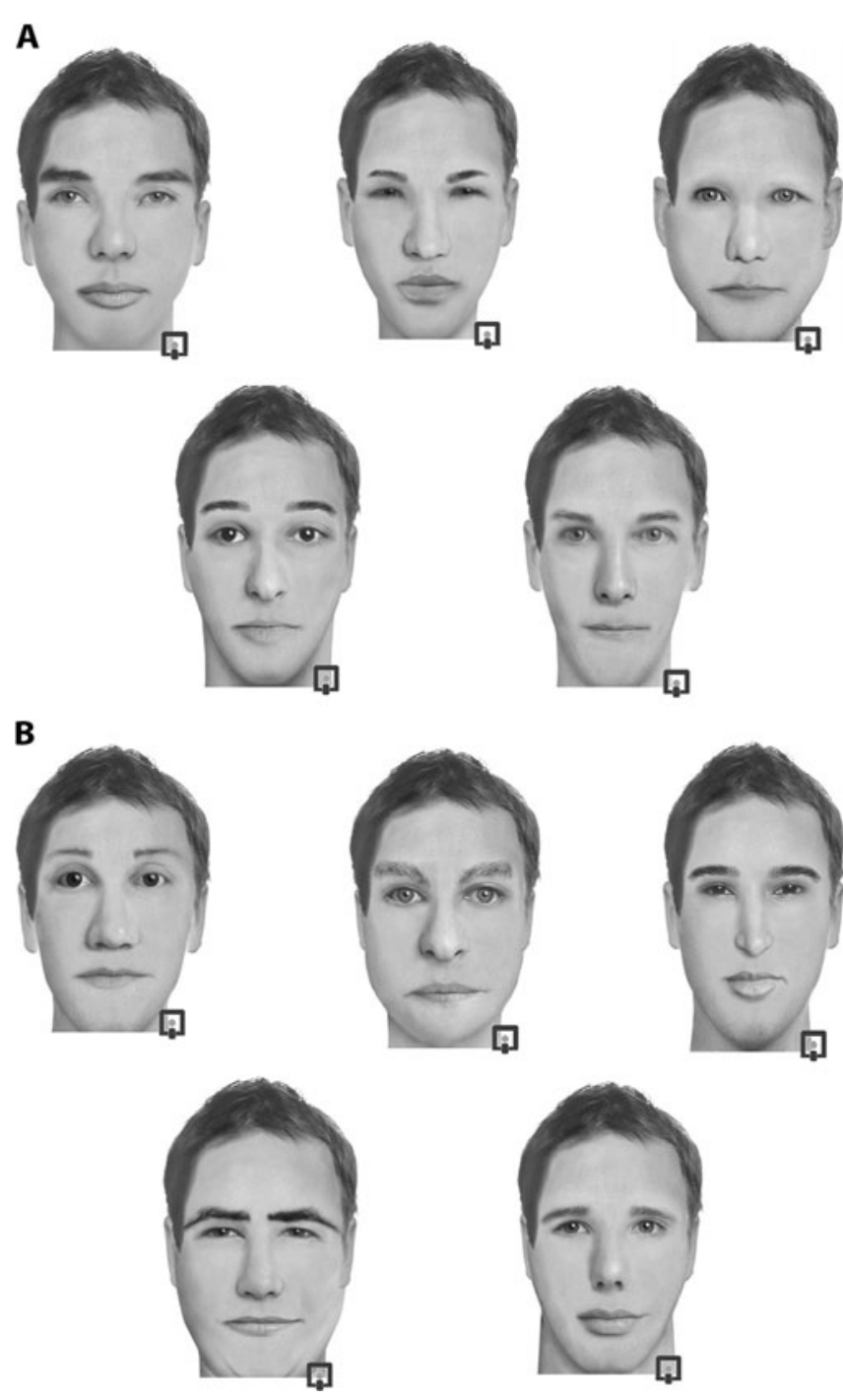

Figure 2. (A) Faces created for the name "Rick." The faces on the top row are those that were later determined not to fit the category; the bottom row are faces that did fit the category. (B) Faces created for the name "Bill." The faces on the top row are those that were later determined not to fit the category; the bottom row are faces that did fit the category.

names and faces. First, a weak version of the hypothesis that we have facial prototypes in mind for specific names would be supported if there was agreement across participants in their matching choices. In other words, matching choices should not be random. Second, a stronger prediction would be that the face most often selected as going with a particular name corresponds to the prototype that was constructed out of the exemplars for that name in Experiment 1.

\footnotetext{
Method

Participants. Participants included 139 Caucasian volunteers (89 women) recruited from the Miami University psychology participant pool, graduate students, and psychology students earning extra credit for participation.
}

Materials and Procedures. The stimuli were $81 / 2 \times 11$ in. cards on which one of the 15 prototype male faces from Experiment 1 (Figure 3 ) were printed. Each of the 15 male names in Table 1 was printed on a second set of $3 \times 5 \mathrm{in}$. cards. The experimenter shuffled the two decks of cards and then laid out the face cards on one side of a large table. Each participant was run individually and was asked to match a name with a face by moving a name card to a face card.

\section{Results}

The dependent variable was the frequency of each name response to each face. The null hypothesis for the weak prediction is, for each face, the probabilities of selecting any given name are equal across names. This was tested using the chi-squared test of constant proportions for all faces, to determine whether participants were assigning some names to faces more frequently than chance would predict (Siegel \& Castellan, 1988). Table 2 contains the frequencies of name responses, as well as the calculated chi-squared value for each row corresponding to a particular prototype face. ${ }^{2}$

It is clear from the table that faces were labeled most often with the name for the prototype face in most cases (10 out of 15). Of these 10, 4 of the faces were labeled with the name that was used to create the face, supporting the strong prediction for these faces.

\section{EXPERIMENT 3 Face-Name Learning}

As demonstrated in Experiment 2, with these particular 15 names and faces, participants tend to agree on which name belongs to which face, at least for the majority of the face stimuli used. This agreement could be an artifact of the matching task, and not a result of an enduring cognitive link between names and faces. Thus, it is possible that participants formed face-name associations only when pressed to perform our matching task. On the other hand, it is possible that the face-name associations illustrated in Experiment 2 arise from enduring cognitive representations.

One means of demonstrating that the matching results do not arise from a stimulus and/or task specific artifact is to show that there are cognitive consequences of a facename prototype relationship. Specifically, if we associate particular facial characteristics with, say, Bob, then to learn that such a face is really a "Tim" may require more training than if the face did in fact belong to a "Bob." We investigate the hypothesis that learning names for faces is facilitated to the extent that the face-name pairing agrees with the face-name matching results of Experiment 2.

We introduce a construct termed association strength (AS) as a metric for how strongly a set of names collectively is associated with a set of faces and defined it for the face prototypes from Experiment 1 based on the frequency that participants in Experiment 2 provided a particular name for a given face in Experiment 1. For example, Table 2 shows that the association value between Bob's face and Bob's name is 41 ; thus, the as- 

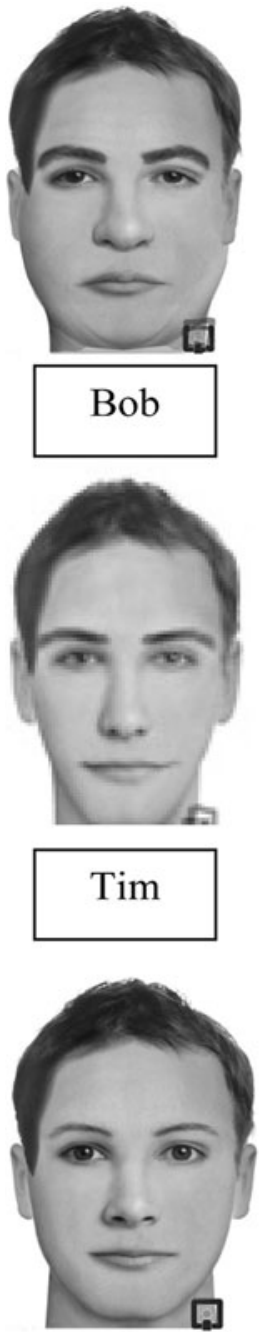

\section{Brian}
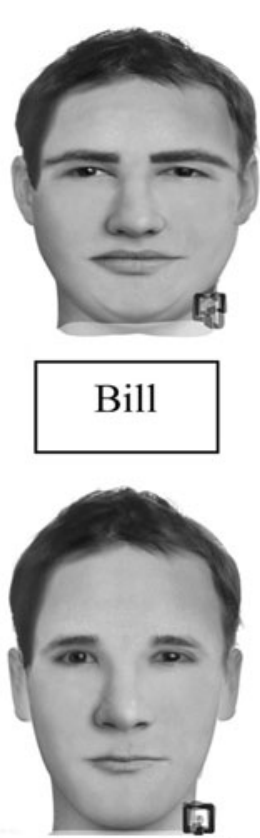

John
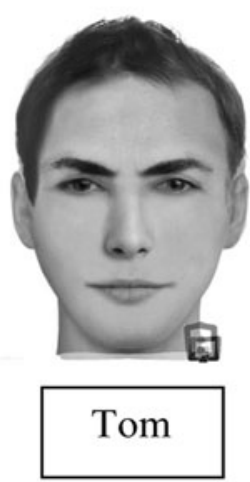
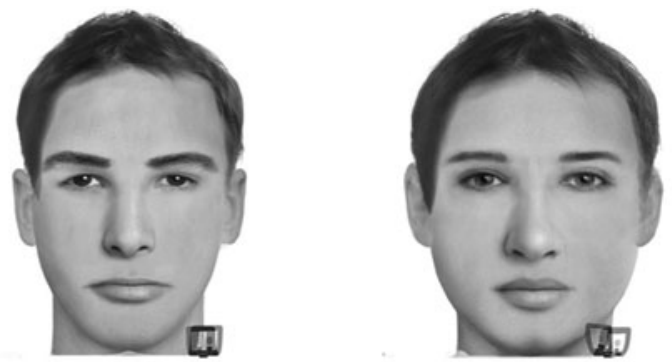

Mark
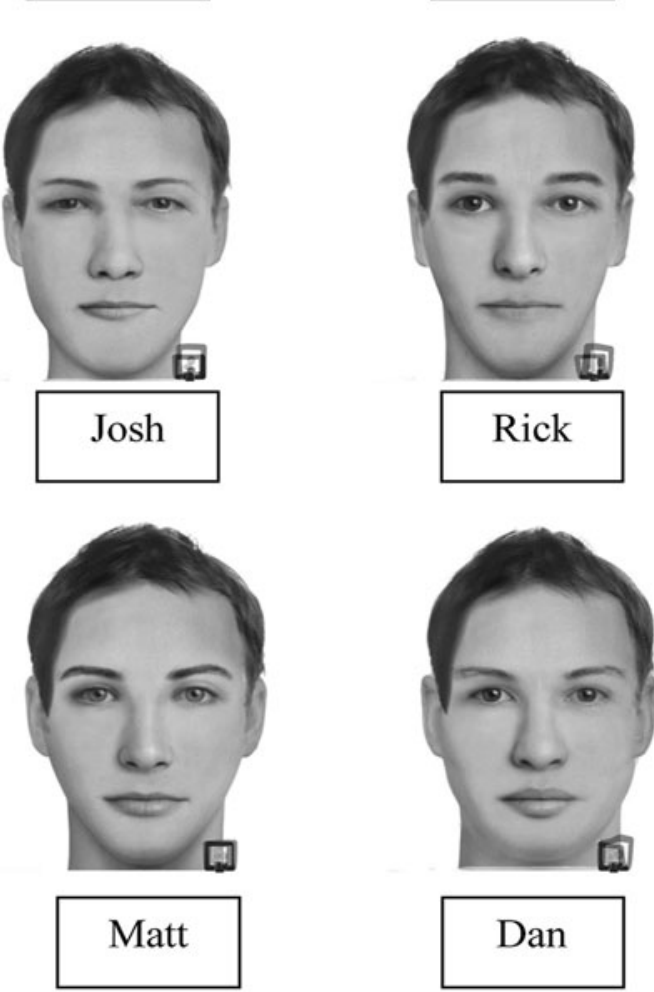

Rick

Joe

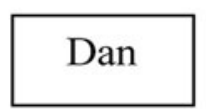

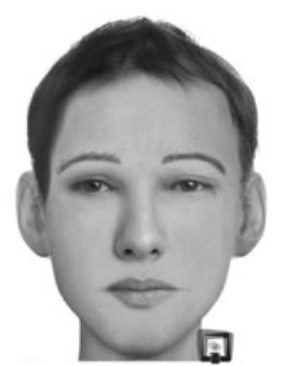

Jason

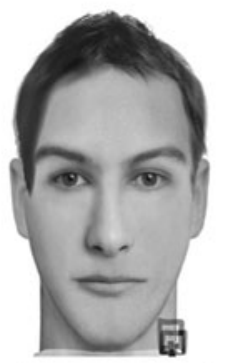

Andy

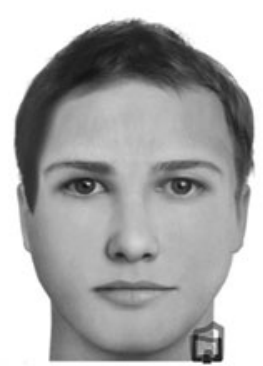

Justin

Figure 3. Prototype faces, created by morphing (Morpher 3.0) exemplar faces (see text).

sociation value for that pair is 41 . A randomization of face-name pairs provided possibilities of pairings for different learning conditions. The sum of the association values for the pairings (AS) reflects how closely that set of names and faces are associated. It was predicted that the more closely the face-name pairs were associated, the fewer trials it would take a participant to learn the association. 


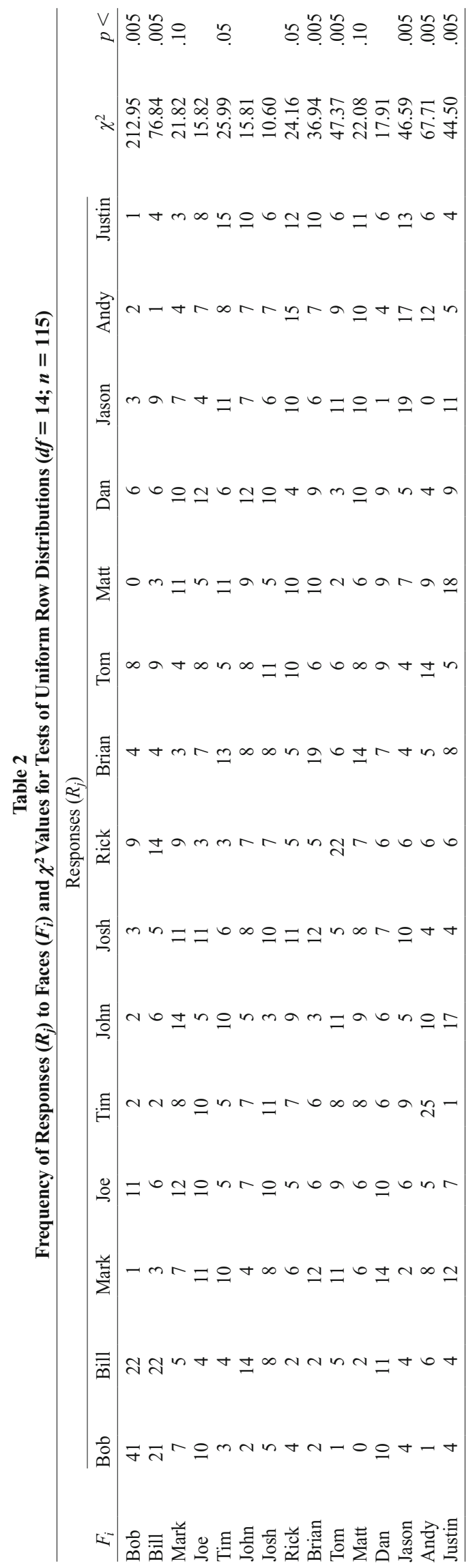

\section{Method}

Participants. The 67 Caucasian participants (44 women), all from Miami University, were volunteer graduate students and a faculty, as well as psychology students earning extra credit for participation.

Materials and Procedures. The 15 prototype faces from Experiment 2 were used as stimuli. Each participant was required to learn which name belonged to each face in a standard learning/identification paradigm. The specific face-name mapping differed across learning conditions as defined by the AS. Using the frequencies of matches from Experiment 2, faces were paired in the following way. For each face-name pair, the association value was determined by how often participants provided a particular name for the face in Experiment 2. The sum of the association values for the pairings, the AS, reflects how closely that set of names and faces are associated. Conditions, ranging from a minimum AS of 39 to a maximum AS of 252 , were generated by randomly assigning names to faces and then inspecting the distribution AS across these associations. Because of the discreteness of the AS metric as defined from the data in Experiment 2, 11 learning conditions resulted.

Participants learned their face-name pairings at a computer over the course of many learning trials. On each trial, the computer displayed one of the prototype faces on the left of the screen along with all 15 name stimuli on the right of the face. After a participant's response, the word "correct" or "incorrect" appeared on the screen, along with the face, and the correct response. The participant then pressed the space bar to start the next trial. For each participant, the stimulus set (15 faces and 15 names) was randomized and sampled without replacement. One run through the set constituted a single learning trial. The dependent variable is trials to criterion, which is defined as 45 correct responses (naming) in a row.

\section{Results}

Table 3 lists the mean number of trials for each AS value. To probe the hypothesis that a higher AS leads to faster learning, we computed Pearson's product-moment correlation to assess the relationship between AS and trials to criterion. As predicted, this correlation was negative $(-.27)$ and significant $[r(64)=-.27, p=.02$, one-tailed $]$. That is, participants with a lower AS took more trials to learn the face-name associations than did the participants that received a higher AS. Given all of the factors that contribute to learning, that the matching frequencies of Experiment 2 account for nearly $8 \%$ of the variance in the present task, is quite remarkable.

\section{DISCUSSION}

The objective of these experiments was to demonstrate the existence of a relationship between facial features and personal names and that this relationship was neither spurious nor artifactual, but that it has consequences for future cognitive tasks. On the basis of our experimental results, the face of an individual did influence what the participants chose for a name in most cases. Also, it was shown that when faces and names are not ideally matched, participants learn this matching more slowly than when faces and names are well matched. To our knowledge, such evidence has not been directly investigated. ${ }^{3}$

The present work may provide explanations for several outstanding questions in the literature on names and faces. First, it has been shown that TOT for people's names can sometimes be resolved with another view of the face (see, e.g., Young, Ellis, \& Flude, 1988). That is, the facial features may be a cue to the name if the name fits the face. 
Table 3

Mean Number of Trials to Criterion for Sequences of Different Association Strength (AS) Values

\begin{tabular}{ccrccc}
\multicolumn{9}{c}{ Different Association Strength (AS) Values } \\
\hline AS & $\begin{array}{c}\text { Trials to } \\
\text { Criterion }\end{array}$ & AS & $\begin{array}{c}\text { Trials to } \\
\text { Criterion }\end{array}$ & AS & $\begin{array}{c}\text { Trials to } \\
\text { Criterion }\end{array}$ \\
\hline 39 & 447.7 & 98 & 518.6 & 194 & 312.0 \\
59 & 420.8 & 111 & 461.4 & 196 & 315.0 \\
80 & 338.2 & 141 & 225.2 & 203 & 275.0 \\
81 & 373.0 & 156 & 235.7 & 220 & 328.6 \\
96 & 435.7 & 171 & 323.2 & 252 & 241.2 \\
\hline
\end{tabular}

Second, the slower learning observed in Experiment 3 could serve to explain why Valentine and Moore (1995) reported that in some cases names are more difficult to learn to associate to particular faces. According to our account, this may be because the name face pairings in Valentine and Moore's study were not of equal association strengths. Finally, the present results provide a possible explanation for Cohen's (1990) finding, where participants who named their face stimuli during learning learned faster and recalled names better than those who were provided with face-name pairing by the experimenter. Specifically, our results suggest that when participants' expectations of what a person's name should look like are met, participants will have fewer naming errors.

Although the goal of this research was to document the existence of facial prototypes for specific names, some speculation as to potential causes of the effect can be made. Future research will be needed to choose among these. Three possible explanations for the source of this effect seem evident. First, it is possible that facial features in the environment are statistically associated with different names. This is certainly true within ethnicity where particular names (Rajesh) would be correlated with certain facial types (Indian). Although this explanation appears outlandish on its face in such a homogenous group (Caucasian male faces and English type names), however, within families the passing down of names (i.e., Robert I, Robert II, etc.) could actually lead to collections of features co-occurring with particular names. Our development of facial prototypes for names is nothing more than observing the structure of family resemblances in the world (Rosch, 1978). Even if true, it is doubtful that this would be a powerful enough influence to produce the type of behavior discussed here.

A second possibility exploits the findings from social psychology. Recall, evidence for the association of names to social characteristics has been obtained (see, e.g., Bruning, Polinko, \& Buckingham, 1998; Mehrabian, 2001), and certain social characteristics have been shown to be associated with distinct facial types (Goldstein, Chance, \& Gilbert, 1994; Shevlin, Walker, Davies, Banyard, \& Lewis, 2003). These two observations could produce an indirect link between names and facial features with social characteristics mediating the relationship. Alternatively, facial prototypes for different names mediate the other two relationships and would be worth investigating in a future mediational design.

Finally, a third explanation is possible having to do with cross-modal interaction between the sound of the name and the physical features of the face (see Melara \& Marks, 1990), a type of perceptual embodiment (Barsalou, 1999). Hence, articulating a name when considering a face may allow the acoustic features of the name to be integrated into the representation of facial features and vice versa. For example, "Bob," acoustically, is a round-sounding name and, hence, may suggest roundness of the face (Sapir, 1929). One idea that supports this hypothesis is the observation that perceived similarity between objects may involve the similarity of their labels (Sloutsky, Lo, \& Fisher, 2001). Embodiment effects have been documented in a wide range of cognitive, social, and emotional activities (e.g., Niedenthal, Barsalou, Winkielman, KrauthGruber, \& Ric, 2005).

The latter idea has been tentatively probed in our lab. Using the face prototypes from Experiment 1, observers rated similarity between pairs of faces (without any labels) which were then modeled using multidimensional scaling analysis. One of the derived dimensions corresponded well to the acoustic properties of the names originally presented to the Experiment 1 participants. What is particularly remarkable about this finding is that the raters in the similarity task never saw the names that were linked to the faces in the construction phase.

\section{AUTHOR NOTE}

We thank David A. Waller for his helpful comments on earlier versions of the manuscript and Robert L. Schaefer, Department of Mathematics and Statistics, Miami University, for his assistance and advice on the statistics. We also thank Kate Karelina, Ryan Foote, and Larissa Grace for their work on collecting data for Experiment 1, and Jeff $\mathrm{H}$. Sholl for his programming of Experiment 3. We also thank Tom Busey, Vicki Bruce, and Michael Wenger for their many helpful suggestions. Correspondence concerning this article should be addressed to R. D. Thomas, Department of Psychology, Miami University, Oxford, OH 45056 (e-mail: thomasrd@muohio.edu).

\section{REFERENCES}

Barsalou, L. W. (1999) Perceptual symbol systems. Behavioral \& Brain Sciences, 22, 577-660.

Bruce, V., \& Young, A. (1986). Understanding face recognition. British Journal of Psychology, 77, 305-327.

Bruning, J. L., PolinKo, N. K., \& Buckingham, J. T. (1998). Connotative meanings of names and nicknames: Changes over twenty-seven years. Psychological Reports, 83, 427-430.

Conen, G. (1990). Why is it difficult to put names to faces? British Journal of Psychology, 81, 287-297.

Ellis, H. D., ShePherd, J. W., \& Davies, G. M. (1979). Identification of familiar and unfamiliar faces from internal and external features: Some implications for theories of face recognition. Perception, 8, 431-439.

English, G., Titchener, E. B., \& Weld, H. P. (1916). Minor studies from the psychological laboratory of Cornell University: I. On the psychological response to unknown proper names. American Journal of Psychology, 27, 430-434.

Goldstein, A. G., Chance, J. E., \& Gilbert, B. (1984). Facial stereotypes of good guys and bad guys: A replication and extension. Bulletin of the Psychonomic Society, 22, 549-552.

IQ Biometrix (1998). Faces (Version 3.0) [Computer software]. Redwood Shores, CA: Author

Kasof, J. (1993). Sex bias in the naming of stimulus persons. Psychological Bulletin, 113, 140-163.

LindSAY, D. S., JACK, P. C., \& Christian, M. A. (1991). Other-race face perception. Journal of Applied Psychology, 76, 587-589.

MaCLin, O. H., \& MaLPass, R. S. (2001). Racial categorization of faces: The ambiguous race face effect. Psychology, Public Policy \& Law, 7, 98-118. 
McWeeny, K. H., Young, A. W., Hay, D. C., \& Ellis, A. W. (1987) Putting names to faces. British Journal of Psychology, 78, 143-149.

Mehrabian, A. (2001). Characteristics attributed to individuals on the basis of their first names. Genetic, Social, \& General Psychology Monographs, 127, 59-88.

Melara, R. D., \& Marks, L. E. (1990). Processes underlying dimensional interactions: Correspondences between linguistic and nonlinguistic dimensions. Memory \& Cognition, 18, 477-495.

Niedenthal, P. M., Barsalou, L. W., Winkielman, P., KrauthGruber, S., \& Ric, F. (2005). Embodiment in attitudes, social perception, and emotion. Personality \& Social Psychology Review, 9, 184-211.

Perrett, D. I., Lee, K. J., Penton-Voak, I., Rowland, D., YoShiKaWA, S., Burt, D. M., ET AL. (1998). Effects of sexual dimorphism on facial attractiveness. Nature, 394, 884-887.

Rosch, E. (1978). Principles of categorization. In E. Rosch \& B. Lloyd (Eds.), Cognition and categorization (pp. 27-48). Hillsdale, NJ: Erlbaum.

SAPIR, E. (1929). A study of phonetic symbolism. Journal of Experimental Psychology, 12, 225-239.

Satran, P. R., \& Rosenkrantz, L. (2004, September). How important is a name? Parenting, 137-143.

Shevlin, M., Walker, S., Davies, M. N. O., Banyard, P., \& Lewis, C. A. (2003). Can you judge a book by its cover? Evidence of selfstranger agreement on personality at zero acquaintance. Personality \& Individual Differences, 35, 1373-1383.

Siegel, S., \& Castellan, N. J. (1988). Nonparametric statistics for the behavioral sciences (2nd ed.). New York: McGraw-Hill.

Sloutsky, V. M., Lo, Y.-F., \& Fisher, A. V. (2001). How much does a shared name make things similar? Linguistic labels, similarity, and the development of inductive influence. Child Development, 72, 16951709.

Valentine, T., Brennen, T., \& Bredart, S. (1996). The cognitive psychology of proper names: On the importance of being Ernest. New York: Routledge.
Valentine, T., \& Bruce, V. (1986). The effect of race, inversion and encoding activity upon face recognition. Acta Psychologica, 61, 259-273.

Valentine, T., \& Moore, V. (1995). Naming faces: The effects of facial distinctiveness and surname frequency. Quarterly Journal of Experimental Psychology, 48A, 849-878.

Young, A. W., Ellis, A. W., \& Flude, B. M. (1988). Accessing stored information about familiar people. Psychological Research, 50, 111-115.

Young, A. W., Hay, D. C., McWeeny, K. H., Flude, B. M., \& Ellis, A. W. (1985). Matching familiar and unfamiliar faces on internal and external features. Perception, 14, 737-746.

\section{NOTES}

1. We chose to include data from only Caucasian participants so as to avoid variables that can exert an overwhelming influence on performance (Lindsay et al., 1991). We limited the names to one gender and ethnicity for the same reason. We were interested in more subtle relationships between names and face characteristics.

2. The provided chi-square values are not independent, that is if a participant matches name $j$ to face $i$, then they can no longer match name $j$ to face $k$.

3. The most similar study in the literature to ours that we could find was English, Titchener, and Weld (1916; cited in Valentine et al., 1996) who showed that participants could attribute physical characteristics to a person based on a name. In this experiment, English et al. presented participants with nonwords (i.e., names), and the task was to describe the person that "must belong to the name." The results were relatively inconsistent, except for a few cases; for instance, "Rupzoiyat" was described as a young man by all participants, and "Boppum" was described as a "large fat man" by 6 out of the 8 participants.

(Manuscript received September 27, 2006; revision accepted for publication January 10, 2007.) 